\title{
Testing the Waters: A Demonstration of a Novel Water Quality Mapping System for Citizen Science Groups
}

\author{
Eric D. Compas* and Suzanne Wade ${ }^{1, f}$
}

\begin{abstract}
Citizen science initiatives are increasingly using new devices, smartphone apps, and interactive websites to improve data quality and collection procedures, better visualize trends and changes, and increase volunteer engagement and retention. This methods paper reports on the development and demonstration of a prototype water quality instrument array and website to modernize volunteer water quality sampling. Using open source software and off-the-shelf components, our device measures GPS location, dissolved oxygen, temperature, conductivity, and $\mathrm{pH}$ at a high sampling rate. Combined with a smartphone app and website, the system provides real-time maps and visualization of water quality data. We demonstrated the device on an 11-day public expedition called "Testing the Waters: A Paddle and Probe Adventure" down the Rock River in Wisconsin. The event was successful in collecting 30,000 GPS-tagged water samples across $324 \mathrm{~km}$ providing a unique profile of the river's water, identifying potential water quality issues, and establishing a baseline for comparison. Through the project and additional volunteer feedback, we learned lessons about a broader-scale adoption including: 1) need to simplify setup and calibration; 2) need for further development of online tools to better communicate with a non-technical audience; and 3) need for a flexible device that works in a variety of situations, e.g., static deployment. The pilot demonstrated the potential of new technology and a low-cost device to expand the types and amount of water quality data collected by citizen monitors.
\end{abstract}

Keywords: water quality; citizen science; monitoring; open hardware; web mapping; real-time; Wisconsin

\section{Introduction}

Water quality monitoring programs have been among the longest-running and successful citizen science programs in the US. Examples include Maryland's Save Our Streams (SOS) program, Michigan's Cooperative Lakes Monitoring Program, and Ohio's Stream Quality Monitoring (SQM) program (Firehock and West 1995; Wilmes 2017). In Wisconsin, the Water Action Volunteer (WAV) program has been active since 1996 and, as of 2015, monitors 751 sites across the state (Stepenuck 2016). Most of these programs rely on simple monitoring protocols with relatively inexpensive field equipment, such as thermometers, chemical kits to measure dissolved oxygen, and D-frame nets for macroinvertebrate sampling. While these time-tested protocols have been used successfully for more than a decade, new and increasingly inexpensive technologies present opportunities to modernize water quality sampling.

Many citizen science programs face challenges to longterm viability for a variety of reasons, including data

\footnotetext{
* Department of Geography, Geology, and Environmental Science, University of Wisconsin-Whitewater, Whitewater, US

University of Wisconsin-Extension, CNRED (Community, Natural Resources and Economic Development), US

‡ Rock River Coalition, US

Corresponding author: Eric D. Compas (compase@uww.edu)
}

quality concerns (Fore et al. 2001; Dickinson et al. 2010; Hochachka et al. 2012; Muenich et al. 2016; Thornton and Leahy 2012), recruitment and retention (Alender 2016; Andow et al. 2016; Baruch et al. 2016), and inability to provide volunteers with immediate feedback (Baruch et al. 2016; Silvertown 2009). Emerging technologies can address many of these concerns and have been successful in other citizen science domains (Sullivan et al. 2009). They have the potential to (1) increase the efficiency of data collection and aggregation, (2) increase the quality of data through verification procedures, and (3) provide more meaningful and immediate feedback to volunteers. Well-designed and integrated websites and apps such as iNaturalist.org allow for peer evaluation, member interaction, and direct volunteer feedback. Additionally, low-cost open source hardware and a new community of "makers" open the door to employing sensors in new and more effective ways (e.g., PublicLab.org). Examples include the Air Quality Egg and the DustDino for air quality monitoring and low-cost weather stations for community weather data gathering.

While water quality monitoring programs have a history of developing "homemade" sampling systems and other innovative equipment (Ely 2008), developing new ways to collect and share data has been a challenge. Compared with citizen science projects requiring only visual observations, 
water monitoring of geochemical characteristics and biodiversity indicators poses technological, resource, and training challenges right from the start (Engel and Voshell 2002; Buytaert et al. 2014). Additionally, the cost and complexity of professional water quality arrays $(\$ 3,000$ to $\$ 10,000$ US) poses a significant hurdle. While some efforts have attempted to increase the use of technology in water projects, successes have been limited. Wisconsin's Water Action Volunteers (http://watermonitoring.uwex.edu/ wav/), while having a website where data can be uploaded and viewed, does not yet show the same innovations evident in projects like eBird or iNaturalist. Attempts to improve water quality tools are under way, such as PublicLab's OpenWaterProject (OpenWaterProject.io), Carnegie Mellon's Flamingo/WaterBot project (http:// www.cmucreatelab.org/projects/Water_Quality Monitoring/pages/Flamingo), Global Lake Ecological Observatory's Lake Observer app (https://wwwllakeobserver.org), and Stroud Water Research Center's Mayfly Data Logger (https://envirodiy.org), which are examples of efforts to decrease the costs of monitoring equipment and expand its adoption. Additional work is needed to lower the costs and accessibility of technological solutions for water quality monitoring.

This article describes a collaborative project between the University of Wisconsin-Whitewater (UWW) and the Rock River Coalition (RRC), a local water monitoring nonprofit organization, to develop a novel water quality instrument array designed from the ground up as a device to bring new technologies to citizen science water monitoring. Both authors are current or past board members of the RRC, and the project emerged from our first-hand experience with volunteers in the field, feedback from volunteer monitors, and personal encounters with the concerns mentioned above. Our goal was to develop and test a prototype system on a limited budget, demonstrate its use, and assess its potential for broader-scale adoption by other citizen science users. Both university students and RRC volunteers served as initial evaluators of the device. Our project demonstrates the promise of new innovations in water quality monitoring by demonstrating a low-cost device that can collect high-quality data with high temporal and spatial resolution and can provide immediate feedback through a cell phone and web interface.
First, we provide an overview of the development of our system and its initial testing and comparisons to traditional instruments. Second, we describe our initial public project, called "Testing the Waters: A Paddle and Probe Adventure," a publicly promoted 11-day expedition down $324 \mathrm{~km}$ of the Rock River in Wisconsin. Finally, we review the lessons of our demonstration project and the potential for broader adoption of the system.

\section{Methods}

The water quality instrument array and data flow architecture

For our prototype system, we used a combination of opensource hardware and off-the-shelf water quality probes to construct a water quality instrument array. The array was paired with a smartphone app and a web server to control and visualize the data collected (Figure 1). During the development process, practitioners from the Rock River Coalition were consulted to ensure that the resulting system would be as layperson friendly as possible. Additionally, both university students (new to water quality monitoring) and several RRC volunteers were used as initial proxies for broader citizen science adoption.

Here's a brief overview of how the system works. First, the smartphone app initiates a sample request through a Bluetooth command. This allows the phone with its GPS to be the main point of control over sampling rates to ensure consistent spatial sampling. Second, the array takes sample values for temperature, $\mathrm{pH}$, dissolved oxygen, and conductivity and returns those values to the app. Finally, the app adds time, date, and location information and sends that information to our web server, where it is stored in a database and displayed on an interactive web page in real time.

\section{Components of the instrument array}

The water array comprises an Arduino Uno microcontroller, a bluetooth chip, a battery pack, a power isolation circuit, and individual controllers for each probe $^{1}$ (Figure 2). Probes include a Maxim DS18B20 temperature probe and three Atlas Scientific kits for $\mathrm{pH}$, dissolved oxygen, and electrical conductivity. The cost of the array components was approximately $\$ 900$ US. All components except for the probes themselves were installed in a water-

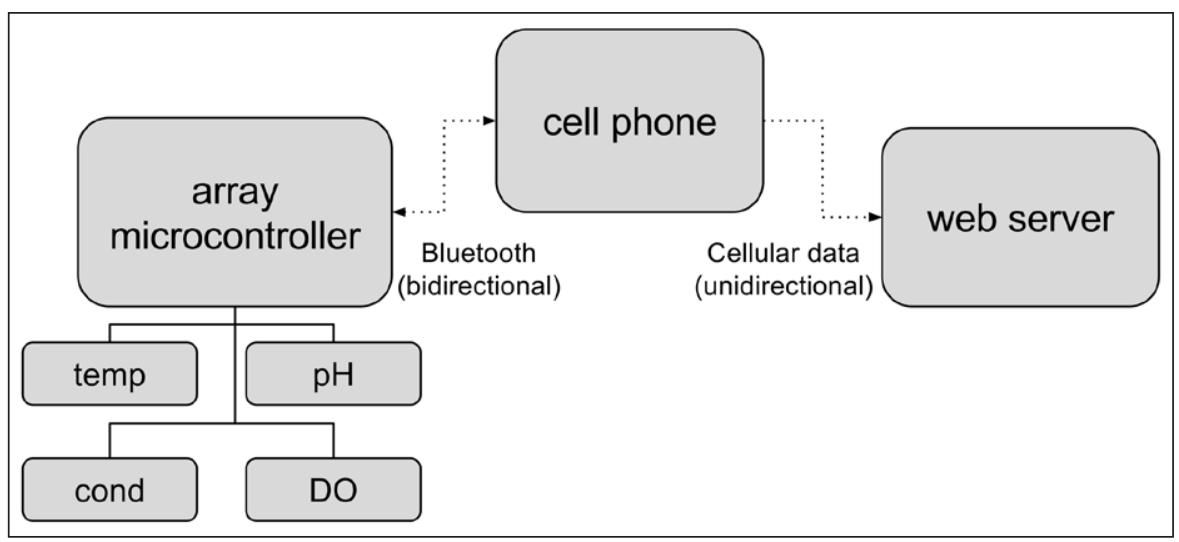

Figure 1: Water quality array system components and the communication between components. 
resistant container for field use (Figure 2). The details and accuracy of each probe is provided in Table $\mathbf{1}$.

Custom code, written in the Arduino development environment, handles the initialization of the device when started and communication between the smartphone app and the individual probes. Our code was written to yield the most accurate measurements that the Atlas Scientific units could provide. We used the maximum number of calibration points for each probe, e.g., $\mathrm{pH}$ of 4,7 , and 11 for the $\mathrm{pH}$ probe, and we used temperature and pressure compensation when available. The first iteration of the code was optimized to make rapid, repeated measurements (once every 10 seconds) and to allow thorough debugging of the device. As such, the device can operate for around 8 hours on a single battery pack. Further optimizations would be needed for a static, long-term deployment, which would include shrinking the size of the device, improving cable management, improving hydrodynamic flow and potential fouling, and extending the sampling time through larger batteries or solar panels.

To mount the testing array on a kayak (Figure 3), we developed a system to attach the water-resistant case to the kayak and hold the probes in the water to take readings. We settled on a design that combined a kayak fishing rod mount with brackets that hold carbon fiber rods with a probe holder at each end (see Figure $\mathbf{3}$ and Github page for construction details). The mount allowed for 1) protecting the probes from underwater objects, 2) swivelling over obstructions, 3) adjustable depth of sampling, and 4) minimizing turbulence and/or bubble formation on the probe or influence from the kayak. With training, our resulting mount takes around 15 minutes to set up and install and allows for minimum adjustment during sampling and clearance for even the smaller, shallower streams we encountered.

\section{The smartphone app}

An Android cell phone was used as the main controller for the array. It provides the system with flexibility over calibration procedures, sampling rates, real-time feedback, and future updates. Requirements for the chosen model included a Bluetooth radio, global positioning system (GPS), and at least eight hours of battery life. We found several carriers with prepaid phones that met these requirements for under US \$40. No physical modifications to the phones were made, and they were stored in waterproof cases while sampling.

For our pilot system, we chose to use MIT's App Inventor (http://appinventor.mit.edu) as a rapid application development (RAD) platform to minimize the technical background and overall development time. We developed two Android apps: One to handle calibration and testing of the water array and another to use for field mapping and communication with the server (available in GitHub library). Sample screens from each are shown in Figure 4.

To simplify operation, we designed the system so that all device setup procedures, calibration, and settings are made within the app. The end user does not need to directly interact with the code on the array or the server.

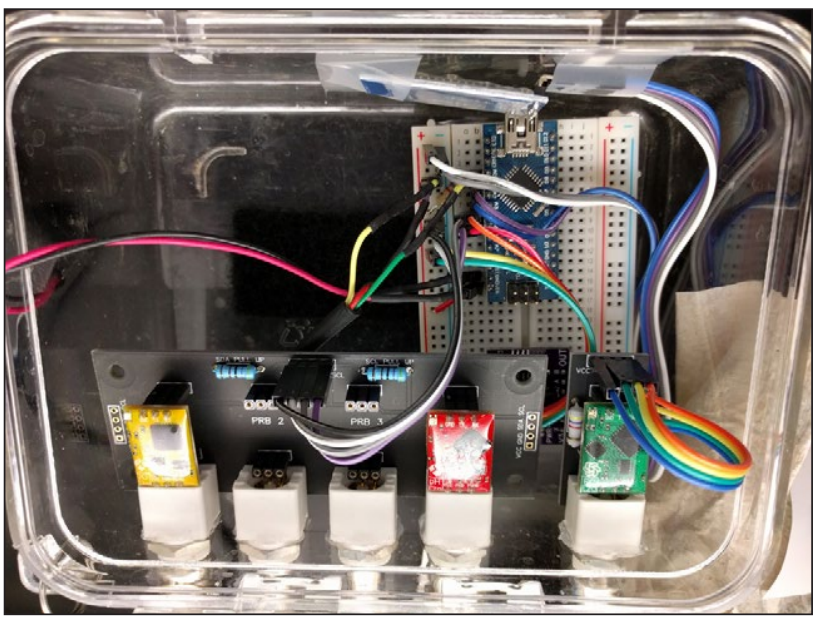

Figure 2: Close-up of the prototype array showing components. Photo by Eric Compas.

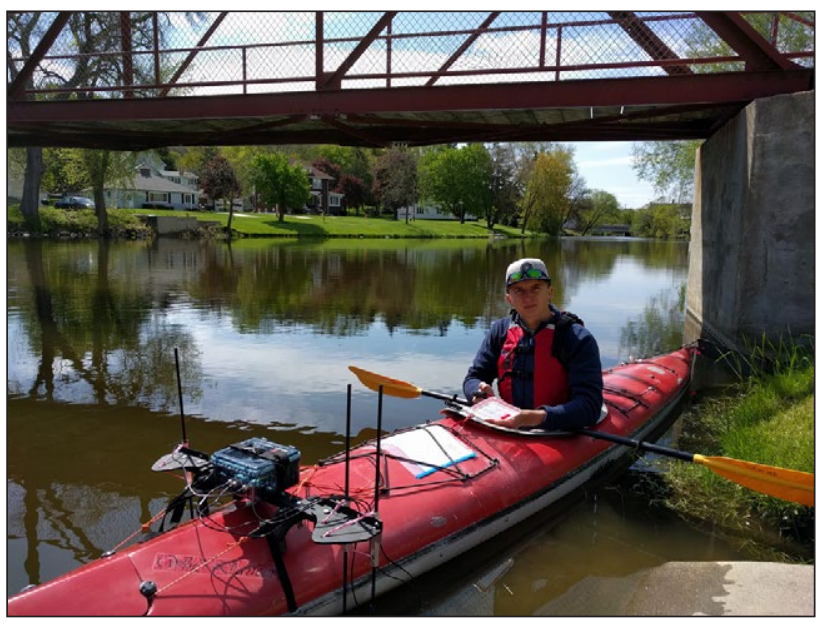

Figure 3: Prototype installed on the front of a kayak with flexible probe mounts. Photo by Eric Compas.

Table 1: Water array probes with vendor-supplied accuracy and sample information.

\begin{tabular}{lllll} 
Probe & Accuracy & Lag time & Calibration type/frequency & Note \\
\hline Temperature & $0.5^{\circ} \mathrm{C}$ & Not specified & Calibration not needed & \\
$\mathrm{pH}$ & \pm 0.02 & $1 \mathrm{sec}$ & $1,2,3$ point; once per year & Compensation for temperature \\
Dissolved oxygen & $\pm 0.2 \mathrm{mg} / \mathrm{L}$ & $\begin{array}{l}0.06 \mathrm{mg} / \mathrm{L} \\
\text { per sec }\end{array}$ & 1 or 2 point; once per year & $\begin{array}{l}\text { Compensation for temperature } \\
\text { and pressure }\end{array}$ \\
Electrical conductivity & $\pm 2 \%$ & $1 \mathrm{sec}$ & 1 or 2 point; once per year & Compensation for temperature
\end{tabular}




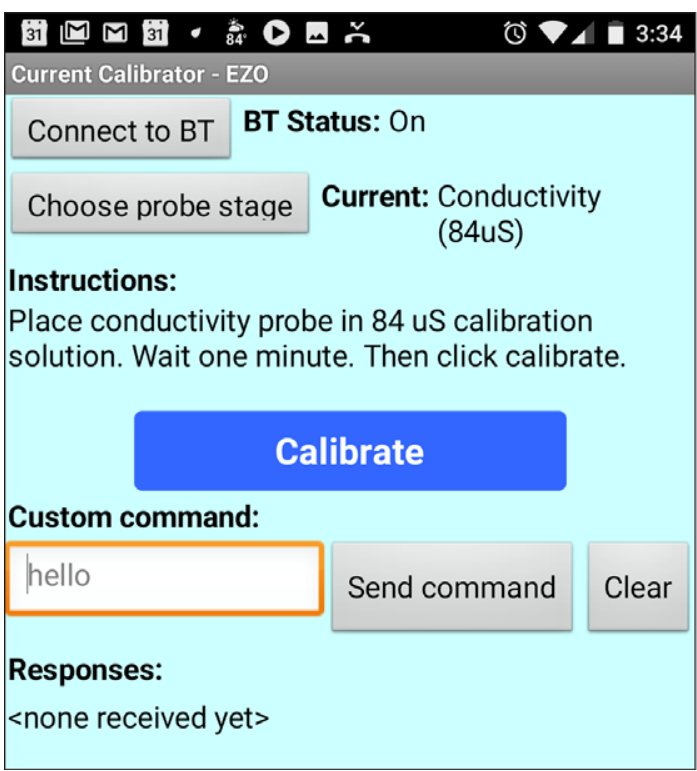

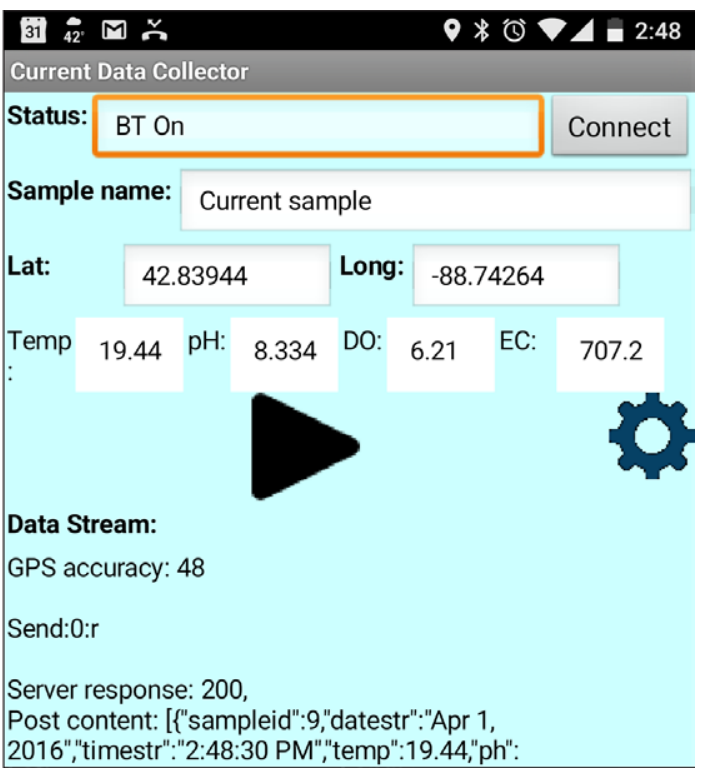

Figure 4: App screens for both the Android calibration app (left) and field collector app (right).

\section{Data and mapping server}

While a server could provide a substantial number of tools, e.g., time and location queries, trend analyses, data editing, and quality control, we chose to focus on two simple functions for our demonstration: Storing sample data on the server and visualizing data on a map.

We assessed two potential platforms: Carto, a commercial cloud-based mapping tool with a free account, and Environmental Systems Research Institute's ArcGIS Server (ESRI 2015), mapping server software that requires your own web server. Both servers allow updates to the database using our app and both have relatively easy-to-use tools to create maps and visualizations. While we were successful in using both platforms to update, store, and visualize our data, we chose to further develop the ArcGIS Server platform given our previous experience with that system and more control over the functionality of the map prototype.

Our website, http://testingwaters.org, provides a realtime interactive map of the data being collected and allows a user to zoom in and out of the data and switch the water quality metric being displayed (see Figure 5). For our public demonstration, we also added the ability to add photos to our map and social media feeds to provide additional context for our event.

\section{Calibration and testing}

Key to the viability of the device for broader adoption by volunteer monitors is the quality and repeatability of the array's data. We had several potential concerns about the device's measurements: (1) potential electrical interference between each probe; (2) irregularities in readings due to movement through water; and (3) calibration "drift" while sampling.

Initial testing for electrical interference - comparing readings of single and paired probes in a sample medium - did show interference between some of the probes. This required a modification of the array electronics and the addition of power isolation circuitry available through
Atlas Scientific. Repeated measurements after the addition of the circuitry did not show the same interference.

Comparing repeated readings of standards also revealed inconsistency with the vendor-specified calibration procedures for the dissolved oxygen and temperature probes. After testing calibration procedures, we found that the USGS's one-point, $100 \%$ saturation, bubbler method (Rounds et al. 2013, p. 55) provided the most consistent results for the dissolved oxygen probe and a one-point calibration of the temperature sensor in an ice bath. We used the vendor supplied three-point calibration for the $\mathrm{pH}$ probe and the two-point conductivity probe. We also designed and used a pre- and post-sample calibration record sheet to record calibration values and to document calibration drift throughout the sample session.

As an additional verification, we compared sample data collected in the field from our array with those from a commonly used instrument, a YSI Professional Plus multiparameter array. Our test included calibrating both units according to vendor specifications (as modified above); mounting both to one of the research kayaks; and paddling a stretch of water with a known temperature/dissolved oxygen/conductivity gradient. Samples were taken approximately every 15 seconds and paired after adjusting for clock differences between the two devices. Our comparison yielded fairly strong correlations between paired readings $(n=152)$ from both devices (a thorough comparison is available in the GitHub library). The $\mathrm{R}^{2}$ values for regressions between the two units for temperature, $\mathrm{pH}$, dissolved oxygen $(\mathrm{mg} / \mathrm{L})$, and conductivity were 0.02 , $0.96,0.89$, and 0.99 , respectively. An example profile for dissolved oxygen taken with both units is shown in Figure 6. The units did show differences in absolute value due to different calibration procedures, and the dissolved oxygen probe in our prototype did show a noticeable lag of approximately two minutes for detecting changes. The low regression score for temperature was attributed largely to the resolution of the two units $\left(0.5^{\circ} \mathrm{C}\right.$ for our prototype and $0.1^{\circ} \mathrm{C}$ for the YSI) and the small variation 


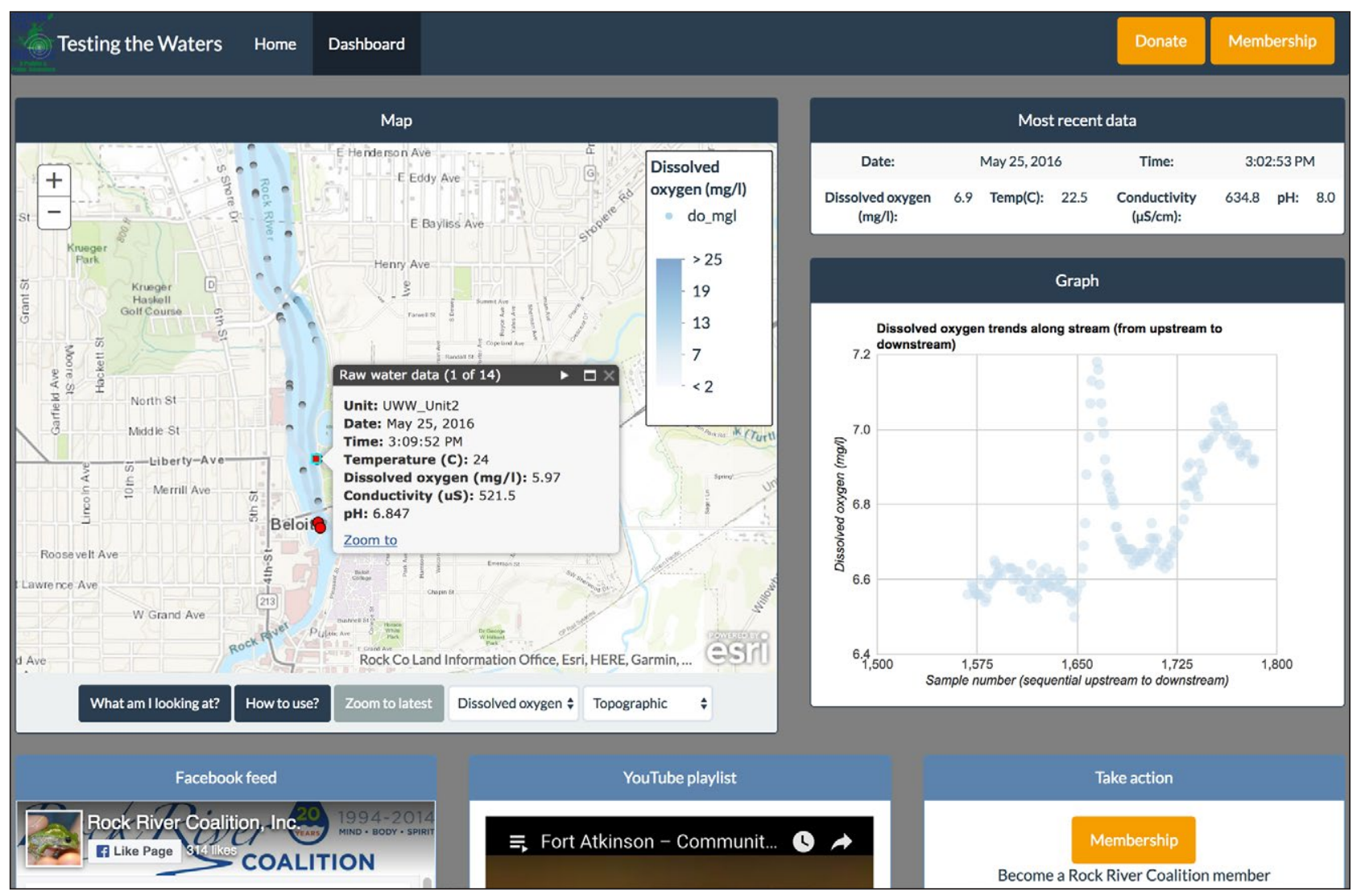

Figure 5: Testing the Waters website (http://testingwaters.org) showing the real-time data and map provided to the public during our event.

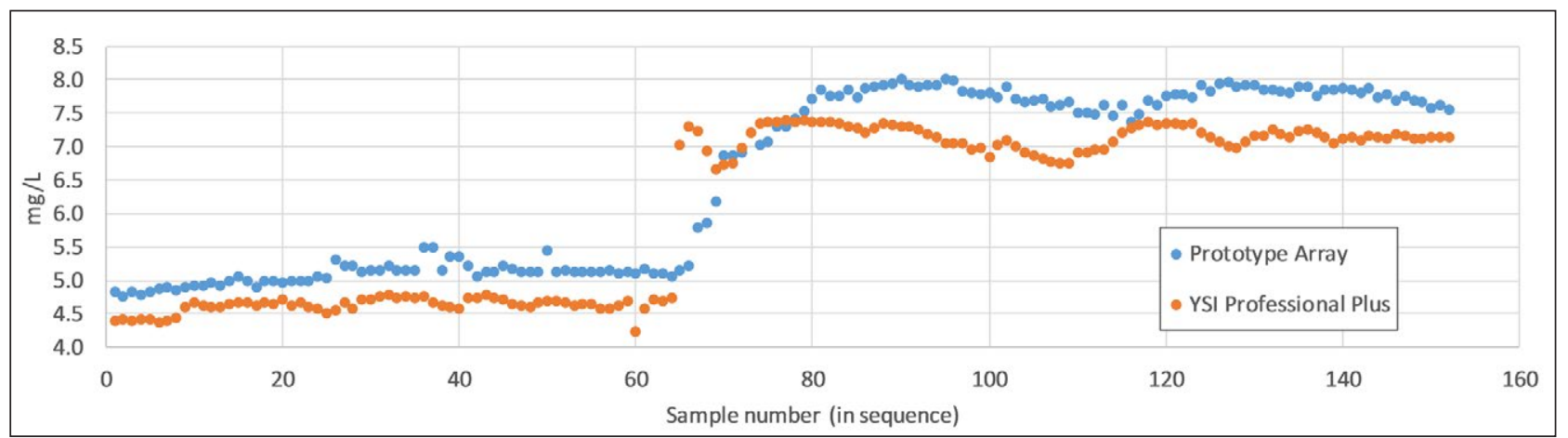

Figure 6: Comparison of dissolved oxygen readings from prototype array and YSI Professional Plus along stream profile.

in temperature across our testing segment. While not a comprehensive comparison between these two devices, this test yielded consistent and comparable results.

\section{Results}

Demonstration project: "Testing the Waters" event In May 2016, the RRC organized and led an 11-day expedition, called "Testing the Waters: A Paddle and Probe Adventure" (TTW), on the Rock River to paddle nearly its whole length - $324 \mathrm{~km}$ - within Wisconsin (Figure 7). The project involved groups of canoe and kayak paddlers taking two of the arrays down the river. In addition to the probes, water samples were taken for phosphorus at local wastewater treatment plants for later analysis. Public presentations were held along the way to discuss water quality and the results from the arrays. The goal was to publicly demonstrate the new technology, increase public awareness of local water quality issues, and recruit new members and new water quality monitors. The public was directed to the website, http://testingwaters.org, to learn about the project and to view the real-time data as the expedition unfolded.

The Rock River within Wisconsin is a low-gradient stream that drains approximately 3,750 square miles of land, with current use dominated by agricultural and residential areas (WI DNR 2011). This section of the river was chosen because it is the main focus of the RRC's water quality monitoring program (part of the Wisconsin WAV program mentioned above) and because it is listed as an "impaired water" under the Clean Water Act, with a total maximum daily load (TMDL) plan approved in 2011. As such, the river serves as an exceptional example of how 


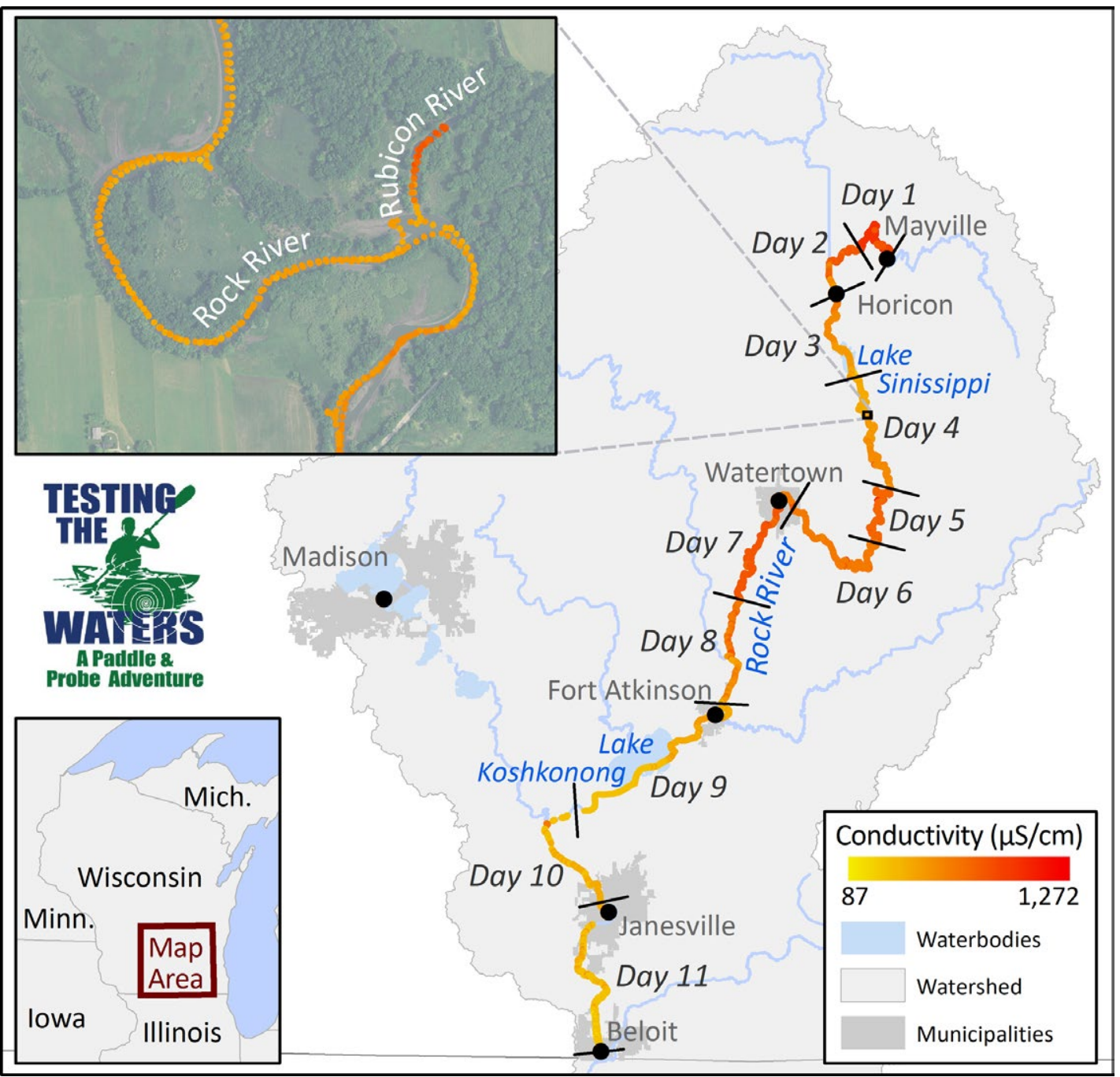

Figure 7: Map showing study area and point sample data for conductivity $(\mu \mathrm{S} / \mathrm{cm})$ for the Testing the Waters event on the Rock River, Wisconsin, with inset showing individual sample from both sampling craft. Sources: ESRI 2014, WisconsinView 2015.

citizen science and public awareness can increase understanding of current water quality issues and the need for monitoring as the TMDL clean-up process unfolds.

For the event, we used two identical units on two different kayaks to increase data quality and to identify any potential inconsistencies between the two units. Both units were calibrated at the beginning of each sample day, and sensor drift was documented by re-measuring calibration standards at the end of each day. We attempted to paddle each boat along the stream centerline to consistently sample the same water within the same 10-15 minute window. The second kayak also sampled larger sloughs along the edge of the stream and major tributaries - by paddling up each side stream for roughly 100 meters - to provide insight into potential sources of changing water quality. For both boats, the sampling interval was set at 10 seconds and the sample depth was set at $15 \mathrm{~cm}$ for all probes. As paddlers sampled, they attempted to keep at least $500 \mathrm{~m}$ of undisturbed water ahead of their boats, but given the amount of boat traffic during the event, this was not always achievable.

Note that while the device was designed for multiple potential citizen science uses, our initial project tested and demonstrated only two - using the device's detailed spatial sampling to provide a baseline of water quality data and its novelty and real-time capabilities to engage the public and to communicate water quality concerns. To assess its eventual use by volunteers, students working on the project as well as several volunteer monitors provided feedback on the device and its operation (discussed below).

\section{Results from event - sampling data}

Our system operated almost without issue for the duration of the trip. Our servers never crashed, and we lost data only twice when the GPS on one of the phones refused to update. Overall, the data between the two units were visually similar, ${ }^{2}$ and where we had calibration issues (conductivity on days 3, 7, and 8, dissolved oxygen on day $6)$, both units measured similar relative change. Overall, we demonstrated the feasibility of our system to collect consistent data at a high spatial resolution.

We also collected a substantial amount of spatially and temporarily comparable data - weather conditions were similar over the whole sampling period. Over the 11 days of paddling we collected a total of 30,264 data points 
(Figures 7 and 8). Additionally, we received no substantial rain during our sample period (less than 0.13 inches), which would have compromised our ability to compare across sample dates due to the resulting changes in water parameters, e.g., changes in temperature, $\mathrm{pH}$, and dissolved oxygen. This allowed a unique view of the river profile and the ability to compare across river segments - something that traditional point sampling does not provide.

Overall, the data show a springtime flow that is relatively healthy from the perspective of the metrics collected. We used a combination of RRC and Milwaukee Riverkeepers water quality targets (RRC does not have approved targets for conductivity and $\mathrm{pH}$ ): dissolved oxygen $>5 \mathrm{mg} / \mathrm{L}, \mathrm{pH}$ from 6 to 9 , conductivity from 150 to $500 \mu \mathrm{S} / \mathrm{cm}$, and temperature $<31.7^{\circ} \mathrm{C}$. Our sample data fit within these acceptable ranges except for high conductivity in a few stream segments. High conductivity values are likely an indication of the river's base and groundwater flow through mostly carbonate rocks and probably not an indicator of poor water quality. None of our samples indicated an acute water quality issue; however, measurements along some stretches indicated potential problems that warrant further investigation.
Reviewing specific parameters reinforces this overall assessment of stream quality. Steadily increasing temperature values reflected the warming spring temperatures throughout the paddle. Spikes visible in the data are not errors - these are mostly warmer temperatures from the second boat paddling into warmer, shallower waters. Interestingly, the larger thermal masses of Lakes Sinissippi and Koshkonong do not show up as colder stretches of water, as would be expected in the transition from cooler spring temperatures to warmer temperatures of summer.

Our $\mathrm{pH}$ values were relatively high, indicating basic/alkaline conditions throughout the river profile. Like conductivity, these alkaline conditions are likely due to the geological substrate - high calcium and magnesium content drawn from the riverbed - which the river flows through and over. Wisconsin fish, in general, can tolerate the high $\mathrm{pH}$, and it may provide some protection from mercury and other heavy metals being absorbed into their bodies (Brown et al. 2010). One study documented that survival of the invasive common carp, Cyprinus carpio, is decreased above a pH of 8 (Heydarnejad 2012). Therefore, high pH may be helping to ameliorate the impact of invasive carp on the river. Also, there is indication of a diurnal cycle of $\mathrm{pH}$ on days 2, 6, 7, and 8. Dissolved carbon dioxide

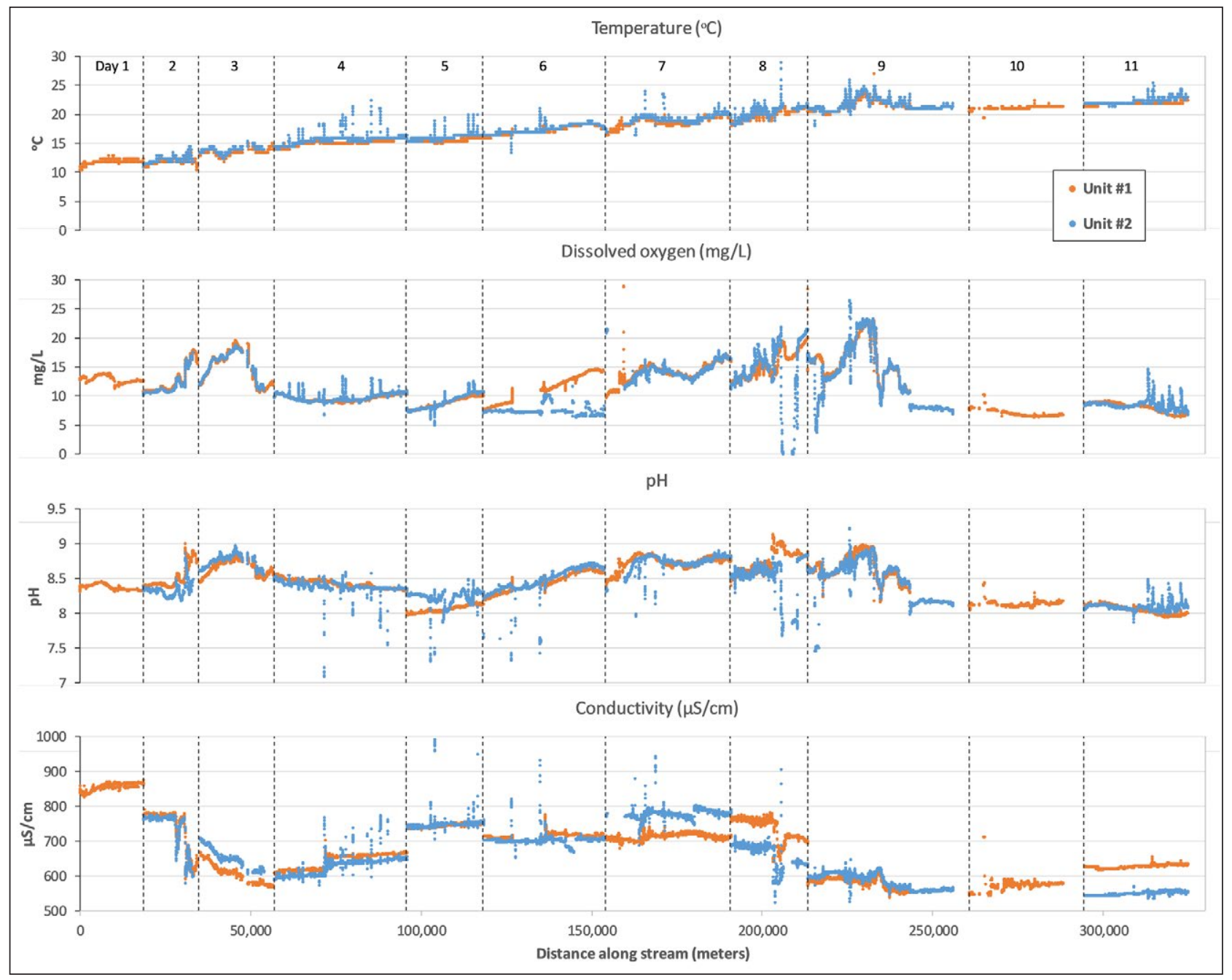

Figure 8: Profile of sample values $(n=30,264)$ along stream centerline for both devices along Rock River, Wisconsin, for Testing the Waters event. Vertical bars represent each sample day during the event (refer to Figure 7). 
generated by respiration of aquatic life can lower $\mathrm{pH}$ values, and because this $\mathrm{CO}_{2}$ is removed throughout the day through photosynthesis, pH values can rise (Fondriest Environmental 2013). The gradual rise in $\mathrm{pH}$ on these days likely indicates stream stretches with healthier aquatic plant communities compared with other stretches. Again, the downward spikes in $\mathrm{pH}$ are not flukes; they are from the second boat's forays into side streams, a pattern we have yet to explain.

Our dissolved oxygen values were relatively high overall. Along our whole route, $60.7 \%$ of our readings are at or above $100 \%$ saturation, which raised concerns about improper calibration or probe bias. However, our units were consistent with one another, and the measurments are likely explained by the seasonably cold water. Supersaturated oxygen levels occur in two situations stagnant water with abundant photosynthesizing plants or with rapid temperature changes. Cold water holds more oxygen and, as the surface of the water warms, becomes supersaturated until equilibrium concentrations at that temperature are reached. This may also explain the relatively high dissolved oxygen readings that we had in Lakes Sinissippi (Day 3) and Koshkonong (Day 9). These larger thermal masses would have higher temperature gradients near the surface. Of note is the general lack of the dissolved oxygen diurnal cycle (lowest in the morning and increasing with photosynthetic activity throughout the day) for several stream segments. In a stream with a healthy plant community, we would expect to see general daily trends such as those visible in Days 5, 6, 7, 8, and the first half of 9. For Days 1, 4, 10, and 11, we see no visible increase in dissolved oxygen as the day progressed. This pattern may indicate compromised aquatic plant communities in these river sections.

Conductivity (or specific conductance), the indirect measure of dissolved solids such as magnesium or calcium, proved to be our most temperamental probe. There was strong agreement between our two units on the change in conductivity, but their absolute values differed for several days (e.g., Days 3 and 7), indicating a difference in calibration. Overall, our profile appears to highlight the role of the two lakes in conductivity. Values are highest before the lakes and drop moving through them (Lake Sinissippi on Day 3 and Lake Koshkonong on Day 9). Dissolved solids such as $\mathrm{CA}^{++}$ions in the water are not the same as suspended solids (which would be measured by a turbidity probe), so we wouldn't necessarily expect the slowing water of the lakes to reduce dissolved solids. However, there may be a relationship between suspended solids and dissolved solids - clay and organic matter may be serving as a flocculant to which ions are binding and settling out of the water column. With conductivity, we did notice the impact of at least one side stream on the Rock. The Rubicon River (see inset in Figure 7) showed a spike in conductivity that appears to have increased the overall levels of the river by around $40 \mu \mathrm{S} / \mathrm{cm}$ - an indication of at least one tributary whose influence was significant on the main stem that warrants further investigation.

Overall, our array provided a novel view of the Rock River in early spring conditions which highlighted the potential for higher spatial sampling to understand our river systems and to serve as a baseline. Additionally, the data indicated specific river segments that need further study to explain the documented patterns.

\section{Results from event - community engagement}

From the perspective of the RRC, the event was one of the most successful hosted by the group during its twenty years of existence. We found that the members of the public who attended our events and school groups were intrigued by the array setup on the kayaks and in the data that we produced.

We held eight community presentations and seven outreach events at local K-12 schools during the trip. Roughly 125 people attended the community events and 50 people joined the daily paddles. Approximately 430 students participated in our school outreach program. At the community presentations, bringing in additional speakers on local topics allowed us to highlight additional water issues such as recent fish studies and wastewater treatment plant innovations for phosphorus reduction. As we expected, attendance at the community presentations and daily paddles was higher in the larger communities and on weekends.

In addition to in-person participation, even more people followed our paddlers on the web. The event was publicized on the RRC website (event signup and schedules), the TTW website (where the data and map were displayed), and Facebook (trip progress and photos), and we tracked analytics for each. For the month of May, the TTW website received 2,328 pageviews from 433 distinct users, while the RRC website received 6,467 pageviews from 1,037 distinct users. Our Facebook page reached 2,963 people ( $450 \%$ increase over previous month) with 3,955 post engagement $(2,800 \%$ increase over previous month). While a direct comparison is difficult, it appears that Facebook was the most effective at reaching the broadest audience, and the TTW website was the least effective. It appears that while there was general interest in the event itself, only a smaller subset of the public was interested in viewing the actual data being produced. Noteworthy, many visitors to the data site were repeat visitors who viewed the map and tracked our progress on multiple occasions. This was corroborated anecdotally with many attendees at the public events noting that they had been following us on their computers or phones.

The event was also successful in garnering local media coverage. It was reported in several local newspapers and received TV coverage by two channels affiliated with national broadcast networks. Given the difficulty for nonprofits to receive coverage for any of their activities, this level of coverage was noteworthy.

Finally, the event led to increased membership in the organization. The RRC documented a $14.5 \%$ increase in membership with 18 new memberships, bringing our total for 2016 to 169 individuals. This event generated substantially more new memberships than any other event in the organization's history. Overall, the event was successful on several fronts: In-person outreach, our web and social media presence, and through local media coverage. The 
response highlights the potential for the next stage of the water array's development - testing and deploying with our water quality volunteers.

\section{Lessons and moving forward}

Overall, our system was successful in providing real-time water quality data throughout the event. We demonstrated that a small team with a modest budget could develop and deploy a system and use it in a public event with a strict schedule. Through our university student and volunteer evaluators, we also learned a great deal about the usability of the device and the modifications that would need to be made before it could be deployed as a tool by unsupervised citizen scientists.

\section{What could have worked better}

We identified two significant concerns with the system that require further refinement. First, the setup and calibration of the device is rather involved and required around 45 minutes every morning to prepare the system and kayaks for launching. The calibration procedure, in particular, required patience and deliberation for us to achieve consistent results. Feedback from volunteers trained on the device indicated that, in its current form, only more experienced monitors would be likely to be successful using the device and that a team of two or more volunteers would be required.

Second, we found anecdotally that the general public did not have enough context to understand the real-time data being provided by the website. Viewers would look at the site, convey to us how "neat" it was, and, when asked, confess that they didn't understand the meaning of the data they were viewing. As other researchers have pointed out (e.g., Newman et al. 2010), the effective design of websites to convey volunteer-collected data is essential, and in our first iteration, we see potential for improvement. Again, before this device could be deployed in a traditional citizen science setting, significant changes need to be made to our interface.

Lessons learned from the public events dealt primarily with the need for more paid assistance during planning, primarily to better engage communities and to enlist support. While we were generally pleased with turnout, we feel we would have had even greater participation if the project had been held in mid June. The dates were chosen to ensure sufficient flow in the headwaters, to allow participation by schools in the basin, and to increase the availability of university students to participate. A full guide on how the project was organized, lessons learned, and recommendations is available on the RRC website (http://rockrivercoalition.org/testing-the-waters/) and in the supplemental file to this article.

\section{Next steps}

The Testing the Waters demonstration provided several insights into how the device could be further refined. First, we are attempting to lower the overall cost to the range that volunteers appear to be willing to spend on their own device (US \$200-300). This price point also would bring the device into a range that smaller water quality nonprofits such as the RRC could afford. Second, we hope to both simplify and shrink the device to be more robust within typical field environments and provide flexible mounting options to be used in other boats and static locations. Third, we believe that battery life could be extended for longer-term, e.g., month-long, static deployments. The devices could then be mounted in streams much like the US Geological Survey's stream gauges to provide longerterm monitoring of stream conditions. Volunteers trained on the device also asked for a canoe mount and simplified cables. Fourth, the calibration and setup procedure can be refined and simplified. We plan to modify our app to record calibration results and to include them in the web database to identify potential user errors and to help quantify the quality of the data being collected. Additionally, the app could flag issues in the field to avoid the collection of poor-quality data.

Finally, our website requires substantial changes for broader-scale deployment. While it was partially effective for outreach during our event, its use for general purpose citizen science monitoring requires several changes. First, it needs the ability to handle multiple users and the respective tools for account management. Second, the maps and visualization of water quality data require a revision based upon feedback from potential users and the public to better understand and find value in the information presented. Finally, the site needs analytical tools to assess trends in water quality through time. For example, the site could include "report cards" on monitored sites to summarize changes through multiple sampling seasons.

\section{Conclusions}

For the Testing the Waters project, we were successful in developing a low-cost, real-time water quality sampling system that can be deployed on a kayak to map water quality along a stream profile. The system includes a smartphone app and a website to store and visualize collected data. During our 11-day public event on the Rock River, we successfully used the system in a real-world setting, collected more than 30,000 data points, and shared the results with the public through our website and multiple community forums. Additionally, we gained initial feedback from volunteer monitors on needed refinements and eventual broader use.

For citizen science water monitoring efforts, the system represents the use of technology to radically change the way in which water quality data is collected and how those data can answer monitoring questions and be shared with the public. With further development, the system could provide water monitoring groups with a powerful set of tools to provide a more detailed view of the surface waters they monitor and the changing conditions - both natural and human-driven - that these waters experience. Realtime data, particularly from static sampling sites, would provide groups with more immediate information about changing water quality conditions and are more likely to identify and respond to water quality threats. The system would supplement, not replace, existing sampling protocols. Overall, the system has the potential to modernize 
and revolutionize the way that groups monitor water quality and convey results to the public.

\section{Supplementary File}

The supplementary file for this article can be found as follows:

- Testing the Waters. A Paddle and Probe Adventure Final Project Report. DOI: https://doi.org/10.5334/ cstp.124.s 1

\section{Notes}

${ }^{1}$ Construction details including documents, photos, Arduino software, and cellphone applications are available at https://github.com/TheGeographer/ water-quality-array.

${ }^{2}$ For sample points taken by each unit within $20 \mathrm{~m}$ on the same day with a consistent calibration, the $\mathrm{R}^{2}$ values for dissolved oxygen, temperature, $\mathrm{pH}$, and conductivity were $0.98,0.80,0.98$, and 0.91 respectively.

\section{Acknowledgements}

We would like to acknowledge grant support from the Wisconsin Department of Natural Resources' River Planning Grant and the University of Wisconsin-Whitewater's Engaged Scholarship Grant, along with multiple donors who contributed to the Testing the Waters project through funding or in-kind donations including phosphorus analysis by several local wastewater treatment plants. Additionally, we gratefully acknowledge the advice and feedback we received on the array and website design and construction from the Rock River Coalition Board, Dr. Mark Riedel, Nancy Sheehan, and Dr. Ozgur Yavuzcetin. Finally, we would like to thank Jojo O'Brien and Caitlin Peterson for their logistical support and the undergraduate research students at UWW who helped to develop and test the water array and website, including Karl Brandstaetter, Michael Smith, Jeff Smyczek, Tyler Tomaszewski, and Porter Vande Voort.

\section{Competing Interests}

The authors have no competing interests to declare.

\section{References}

Alender, B. 2016. Understanding volunteer motivations to participate in citizen science projects: A deeper look at water quality monitoring. Journal of Science Communication, 16(3). DOI: https://doi.org/10.22323/2.15030204

Andow, DA, et al. 2016. Recruitment and Retention of Volunteers in a Citizen Science Network to Detect Invasive Species on Private Lands. Environmental Management, 58(4): 606-618. DOI: https://doi.org/10.1007/ s00267-016-0746-7

Baruch, A, May, A and Yu, D. 2016. The motivations, enablers and barriers for voluntary participation in an online crowdsourcing platform. Computers in Human Behavior, 64: 923-931. DOI: https://doi.org/10.1016/j. chb.2016.07.039

Brown, D, et al. 2010. The relationship between Adirondack lake $\mathrm{pH}$ and levels of mercury in yellow perch. Journal of Aquatic Animal Health, 22(4): 280-290. DOI: https://doi.org/10.1577/H10-005.1

Buytaert, W, et al. 2014. Citizen science in hydrology and water resources: Opportunities for knowledge generation, ecosystem service management, and sustainable development. Hydrosphere, 2: 26. DOI: https://doi. org/10.3389/feart.2014.00026

Dickinson, JL, Zuckerberg, B and Bonter, DN. 2010. Citizen Science as an Ecological Research Tool: Challenges and Benefits. Annual Review of Ecology, Evolution, and Systematics, 41(1): 149-172. DOI: https:// doi.org/10.1146/annurev-ecolsys-102209-144636

Ely, E. 2008. Volunteer monitoring and the democratization of science. The Volunteer Monitor, 19(1): 1-5.

Engel, SR and Voshell, JR. 2002. Volunteer Biological Monitoring: Can It Accurately Assess the Ecological Condition of Streams? American Entomologist, 48(3): 164-177. DOI: https://doi.org/10.1093/ae/48.3.164

ESRI. 2015. ArcGIS Server version 10.2.1.

Firehock, K and West, J. 1995. A Brief History of Volunteer Biological Water Monitoring Using Macroinvertebrates. Journal of the North American Benthological Society, 14(1): 197-202. DOI: https:// doi.org/10.2307/1467734

Fondriest Environmental. 2013. pH of Water. Environmental Measurement Systems. Available at: http:// www.fondriest.com/environmental-measurements/ parameters/water-quality/ph/ [Accessed August 29, 2017].

Fore, LS, Paulsen, K and O'Laughlin, K. 2001. Assessing the performance of volunteers in monitoring streams. Freshwater Biology, 46(1): 109-123. DOI: https://doi. org/10.1111/j.1365-2427.2001.00640.x

Heydarnejad, MS. 2012. Survival and growth of common carp (Cyprinus carpio L.) exposed to different water pH levels. Turkish Journal of Veterinary and Animal Sciences, 36(3): 245-249.

Hochachka, WM, et al. 2012. Data-intensive science applied to broad-scale citizen science. Trends in ecology \& evolution, 27(2): 130-137. DOI: https://doi. org/10.1016/j.tree.2011.11.006

Muenich, R, et al. 2016. The Wabash Sampling Blitz: A Study on the Effectiveness of Citizen Science. Citizen Science: Theory and Practice, 1(1). DOI: https://doi. org/10.5334/cstp.1

Newman, G, et al. 2010. User-friendly web mapping: Lessons from a citizen science website. International Journal of Geographical Information Science, 24(12): 1851-1869. DOI: https://doi.org/10.1080/13658816 .2010 .490532

Rounds, SA, Wilde, FD and Ritz, GF. 2013. Chapter A6 Field Measurements, Section 6.2 Dissolved Oxygen. In: National Field Manual for the Collection of Water-Quality Data, 55. USGS. Available at: http://water.usgs.gov/ owq/FieldManual/Chapter6/6.2_ver3.pdf [Accessed June 5, 2014].

Silvertown, J. 2009. A new dawn for citizen science. Trends in Ecology \& Evolution, 24(9): 467-471. DOI: https://doi.org/10.1016/j.tree.2009.03.017 
Stepenuck, K. 2016. History of Water Action Volunteers (WAV) and Citizen Monitoring in Streams. In: 38th Annual Wisconsin Lakes Partnership Convention. Stevens Point, WI. Available at: http://www.uwsp.me/ cnr-ap/UWEXLakes/Documents/programs/convention/2016/FridayConcurrent/Session8/KrisStepenuck_HistoryofWAVandCitizenMonitoringinStreams. pdf [Accessed August 29, 2017].

Sullivan, BL, et al. 2009. eBird: A citizen-based bird observation network in the biological sciences. Biological Conservation, 142(10): 2282-2292. DOI: https://doi. org/10.1016/j.biocon.2009.05.006

Thornton, T and Leahy, J. 2012. Trust in Citizen Science Research: A Case Study of the Groundwater Education Through Water Evaluation \& Testing Program1 Trust in Citizen Science Research: A Case Study of the Groundwater Education Through Water Evaluation \& Testing Program. Journal of the American Water Resources Association, 48(5): 1032-1040. DOI: https:// doi.org/10.1111/j.1752-1688.2012.00670.x

Wilmes, MK. 2017. DEQ - Cooperative Lakes Monitoring Program. Available at: http://www.michigan.gov/ deq/0,4561,7-135-3313_3681_3686_3731-195536-,00.html [Accessed August 29, 2017].

Wisconsin Department of Natural Resources. 2011. Total Maximum Daily Loads for Total Phosphorus and Total Suspended Solids in the Rock River Basin. Available at: http://dnr.wi.gov/water/wsswimsdocument.ashx?documentseqno $=58866117$ [Accessed February 17, 2018].

How to cite this article: Compas, ED and Wade, S. 2018. Testing the Waters: A Demonstration of a Novel Water Quality Mapping System for Citizen Science Groups. Citizen Science: Theory and Practice, 3(2): 6, pp.1-11. DOI: https://doi.org/10.5334/ cstp.124

Submitted: 05 September $2017 \quad$ Accepted: 13 August $2018 \quad$ Published: 19 December 2018

Copyright: ( 2018 The Author(s). This is an open-access article distributed under the terms of the Creative Commons Attribution 4.0 International License (CC-BY 4.0), which permits unrestricted use, distribution, and reproduction in any medium, provided the original author and source are credited. See https://creativecommons.org/licenses/by/4.0/.

] $\mathbf{u}[\quad$ Citizen Science: Theory and Practice is a peer-reviewed open access journal published by Ubiquity Press. 